\title{
HIDATIDOSIS HUMANA: ECOGRAFÍA DE CAMPO PARA LA DETERMINACIÓN DE GRUPOS DE ALTO RIESGO EN LA EVALUACIÓN DE UN PROGRAMA DE CONTROL.(1)
}

Edmundo LARRIEU (2), Bernardo FRIDER (3), Gustavo ANDREANI (4), Georgina ANDREANI (4), Alberto AQUINO (5) \& Reinaldo DE LA FUENTE (5).

\begin{abstract}
RESUMEN
El desarrollo de equipos ultrasonográficos portátiles ha permitido incorporar esta técnica a los métodos de detección precoz de la Hidatidosis Humana.

En esta experiencia fueron efectuadas 690 ecografías, hallándose un $5.51 \%$ de imágenes compatibles en población general y un $12.24 \%$ en grupos de riesgo (convivientes de casos operados).

Se observó una disminución significativa de los porcentajes de infección en el hombre en población general en las áreas bajo programa de control, utilizándose las encuestas ecográficas para esta determinación.

Se concluyó sobre la posibilidad de incorporar la ecografía a los sistemas de vigilancia epidemiológica de la hidatidosis humana.
\end{abstract}

PAlABRAS ClAVES: Hidatidosis, Ecografía, Grupos de Riesgo, Control.

\section{INTRODUCCION}

La evolución tecnológica ha permitido mejorar en forma notoria los sistemas de detección por imágenes ante situaciones clínicas de hidatidosis humana. Así, en pacientes con cuadros clínicos compatibles con hidatidosis estos sistemas de deteccion pueden ubicar el organo afectado ${ }^{11}$.

Asimismo, el uso de uno de estos métodos, la ecografía, en encuestas de población puede resultar en la visibilización de imágenes compatibles con hidatidosis en personas sin síntomas clínicos de la enfermedad".

Un importante aporte en este sentido lo constituye el desarrollo de equipos portátiles de ecografía, lo que ha permitido incorporar a esta técnica entre los métodos de detección precoz de la hidatidosis humana en poblaciones aparentemente sanas. $1,2, \ldots y$.

En el presente trabajo se utiliza la ecografía como tecnología apropiada de apoyo a un Programa de Control de la Hidatidosis de características integrales, con el objetivo de determinar la prevalencia de la hidalidosis humana en un área endémica y evaluar posteriormente el impacto de las medidas aplicadas en la modificación de la tasa de trasmisión al hombre.

También se propone determinar en áreas

(1) Trabajo cooperativo entre el Consejo Provincial de Salud Pública de Río Negro y la Municipalidad de la Ciudad de Buenos Aires, Argentina.

(2) Jefe Dpt: Zoonosis Salud Pública de Río Negro, Prof. Cátedra de Epidemiologia Facultad de Veterinaria de la U.N. La Pampa.

(3) Unidad Clínica Médica, Hospital Arzerich, Buenos Aires, Argentina.

(4) Hospital Ñorquinco, Salud Pública de Río Negro, Argentina.

(5) Coordinadores de Salud Ambiental, Salud Pública de Río Negro, Argentina.

Dirección para la correspondencia: Dr. Edmundo Larrieu. Laprida 240, 8500 Viedma, Río Negro, Argentina. 
LARRIEU, E.; FRIDER, B.; ANDREANI, G.; ANDREANI, G.; AQUINO, A. \& DE LA FUENTE, R. - Hidatidosis humana: ecografia de campo para la determinación de grupos de alto riesgo en la evaluación de un programa de control. Rev. Inst. Med, Irop. S. Paulo, 31(4):267-270, 1989.

endémicas la posible existencia de grupos humanos de mayor exposición al riesgo sobre los cuales volcar mayores recursos económicos y tecnológicos, tanto en acciones de control como en su diagnóstico precoz.

\section{MATERIALES Y METODOS}

Fueron efectuadas en lotal 689 ecografías, utilizándose para el estudio un ecógrafo portátil de tiempo real y alta resolución, con transductor lineal y convertidor analógico digital, marca Aloka modelo SSD $210 \mathrm{DK}$ con sistema de registro polaroid, siendo los criterios de positividad utilizados (determinación de imágenes compatibles con Hidatidosis) y la técnica de estudio descriptas suficiententente en trabajos previos. 1.2,3

Los grupos controlados pertencen a:

Gupo A: 542 pobladores sin sintomatología clínica de Hidatidosis de edad media 25.44 años $+/-$ 19.95, de concurrencia voluntaria ante la promoción efectuada por agentes sanitarios del Programa de Atención Primaria de la Salud.

Grupo B: 147 pobladores sin sintomatología clínica de Hidatidosis de edad media 23.35 anos $+/-17.90$, convivientes con casos humanos de hidatidosis operados en años anteriores.

Los estudios se efectuaron en áreas urbanas y rurales de las localidades de Norquinco, Pilcaniyeu y El Bolsón, que se encuentran compreendidas en la zona de aplicación del Programa de Lucha Contra la Hidatidosis de la Provincia de Rio Negro, Argentina; puesto en marcha en 1979 y basado en la desparasitación canina sistemática con Praziquantel, educación sanitaria, control de faena y vigilancia epidemiológica de la hidatidosis humana. 6.8

La población total dèl área comprendo 14.556 pobladores.

\section{RESULTADOS}

Grupo A: Estudiado para la descripción de la situación de la Hidatidosis en el área y evaluación de la efectividad de la medidas de Control: La información se presenta en los cuadros 1 y 2 , indicativos de una prevalencia inicial de la enfermedad en población aparentemente sana del $5.51 \%$ de imágenes quísticas compatibles. Estos porcentajes aumentaron significativamente con la edad, no hallándose diferencias entre sexos.

Los resultados comparativos de las encuestas efectuadas en el área de aplicación de medidas de control, con dos años de diferencia, muestran disminución en los porcentajes de aparición de imágenes compatibles, siendo la diferencia observada estadísticamente significativa. $(\mathrm{P}<0.05$, prueba de Chi cuadrado).

\section{CUADRO I}

Castastro ecográfico de Hidatidosis humana en población asintomática en areas de aplicación de Programa de Control. Río Negro, 1984/86

\begin{tabular}{lrc}
\hline Ecografia & 1984 & 1986 \\
\hline Realizadas & 272 & 270 \\
Positivas & 15 & 11 \\
Porcentaje & 5.51 & 4.07 \\
\hline
\end{tabular}

CUADRO 2

Catas tro ecográfico de Hidatidosis humana en población sintomática según edad y sexo. Río Negro, 1984/86

\begin{tabular}{lccc}
\hline Grupos de edad & $\begin{array}{c}\mathrm{H} \\
\mathrm{n}(\%)\end{array}$ & $\begin{array}{c}\text { Sexo } \\
\text { n\% }(\%)\end{array}$ & $\begin{array}{c}\text { Total } \\
\text { n\% }(\%)\end{array}$ \\
\hline $0-10$ años & $97(3.09)$ & $80(2.59)$ & $177(2.87)$ \\
$11-20$ años & $57(3.50)$ & $63(3.17)$ & $120(3.63)$ \\
$21-+$ años & $122(5.73)$ & $123(8.94)$ & $542(4.79)$ \\
\hline Total & $276(4.71)$ & $266(4.88)$ & $542(4.79)$ \\
\hline
\end{tabular}


LARRIEU, E.; FRIDER, B.; ANDREANI, G.; ANDREANI, G.; AQUINO, A.\& DE LA FUENTE, R. - Hidatidosis humana: ecografía de campo para la determinación de grupos de alto riesgo en la evaluación de un programa de control. Rev. Inst. Med. trop. S. Paulo, 31(4):267-270, 1989.

Grupo B: Estudiado para la determinación de grupos de alto riesgo: Los estudios en convivientes de casos operados de Hidatidosis, presentados en cuadros 3 y 4 , indicaron un $12.24 \%$ de imágenes quísticas compatibles con Hidatidosis, presentándo-se una elevada ocurrencia en todos los grupos de edad. Las diferencias en positividad entre este grupo y los controles, población general de la misma localidad, son estadísticamente significativos. $(\mathrm{P}<0.05$, prueba de Chi cuadrado).

\section{CUADRO 3}

Estudio ecográfico de Hidatidosis humana en población asintomática conviviente de casos operados. Según edad. Río Negro, 1986

\begin{tabular}{ccc}
\hline Grupos de edad & Realizadas & $\begin{array}{c}\text { Positivas } \\
\text { n! (\%) }\end{array}$ \\
\hline $0 / 10$ años & 47 & $5(10.63)$ \\
$11 / 20$ años & 38 & $2(5.26)$ \\
$21 /+$ años & 62 & $11(17.74)$ \\
\hline Total & 147 & $18(12.24)$ \\
\hline
\end{tabular}

\section{CUADRO 4}

Estudio ecográfico de Hidatidosis lıumana en población asintomática. Población general y convivientes casos operados. Rio Negro, 1986

\begin{tabular}{lcc}
\hline Grupo de estudio & Realizadas & $\begin{array}{c}\text { Positivas } \\
\text { n\% }(\%)\end{array}$ \\
\hline Poblacion general & 270 & $11(4.07)$ \\
Convivientes & 147 & $18(12.24)$ \\
\hline
\end{tabular}

\section{DISCUSION}

Los resultados de la presente experiencia confirman la utilidad de la ecografía tanto en el diagnóstico precoz de la hidatidosis humana 1.2 .7 .7 como asimismo aplicada a sistemas de vigilancia epidemiológica de la hidatidosis en el hombrel.2.,

Se ha señalado la importancia de la obtención de información básica sobre la hidatidosis en forma previa al establecimiento de medidas de control para posteriormente evaluar su efectividad en la interrupción de la transmisión a la población humana.
Todo programa de control, por este motivo, debería establecer un sistema de vigilancia para la detección, seguimiento y registro de los casos de hidatidosis que se produzcan en el área bajo controls...11.

En el caso de la Provincia de Río Negro, la disminución del $26 \%$ en el hallazgo de imágenes compatibles en población general del área bajo control en dos años de tareas (si bien observada en una muestra que aunque heterogénea y amplia no es seleccionada sistematicamente) se corresponde con la evolución observada en la hidatidosis humana del área medida con los indicadores tradicionalmente utilizados (número de casos nuevos por año, tasa de prevalencia serológica en estudios de cohortes) que indicaran una disminución del $75 \%$ en 7 años de trabajo"

De acuerdo a esto, las encuestas ecográficas prodrían ser utilizadas con la finalidad de determinar el número de casos de hidatidosis en una región (obtención de información básica) y para la medición de la transmisión en el pasado reciente (evaluación del impacto epidemiológico de los programas de control).

Ellas permitirian acortar el intervalo de tiempo transcurrido entre la ingestión de huevos de Echinococcus granulosus y la detección del quiste en forma previa a la aparición de sintomatologia clínica; en igual forma a las encuestas inmunológicas tradicionalmente utilizadas, con la ventaja de presentar un mayor grado de sensibilidad 1.2.3.

Así, la ecografía se presenta como un método de campo nuevo que puede ser aprovechado por los Programas de Control en forma complementaria o alternativa a la encuesta serológica. La elección requerirá el disponer de los equipos adecuados y de operadores entrenados que garanticen los resultados diagnósticos. En oposición a ello, la encuesta serológica mantiene sus ventajas en virtud a la sencillez de su ejecución y la escaza tecnología requerida.

Considerado que la Estrategia de Atención Primaria de la Salud indica la necesidad de volcar los esfuerzos y recursos hacia los grupos de mayor exposición al riesgo, debe merecer especial atención el alto porcentaje de imágenes compatibles hallados en el grupo de convivientes. Las diferencias estadísticas entre estos y la población general parecen indicar la existencia de microfocos familiares de mayor 
LARRIEU, E.; FRIDER, B.; ANDREANI, G.; ANDREANI, G.; AQUINO, A.\& DE LA FUENTE, R. - Hidatidosis humana: ecografia de campo para la determinación de grupos de alto riesgo en la evaluación de un programa de control. Rev. Inst. Med. trop. S. Paulo, 31(4):267-270, 1989.

nivel de contaminación ambiental con huevos de Echinococcus granulosus o una mayor susceptibilidad a la infección ligada a aspectos inmunitarios por ahora no aclarados.

En cualquier caso, y desde un punto de vista clínico, queda asentada la necesidad de incorporar en forma rutinaria estudios para la detección precoz de la hidatidosis en convivientes de pacientes operados domiciliados en áreas con alta prevalencia de esta enfermedad.

\section{SUMMARY}

\section{Human hydatidosis: field ecography to detect groups of risk and to evaluate the control program}

The development of small ultrasonographic equipment has permitted to incorporate this technique to the methods of early detection of Human Hydatidosis.

689 ecographies were carried out in this experience, and $5.51 \%$ of compatible images in the whole population, and $12.24 \%$ in groups of risk (those living together with the operated ones) were found. It was observed a significant decrease in the infection percentages in man in the whole population of areas under Control Program, using the ecographic screening.

In conclusion, ecography might be incorporated to the epidemiologic surveillance system of human Hydatidosis.

\section{REFERENCIAS BIBLIOGRÁFICAS}

1. FRIIDER, B.; LARRIEU, E.; ODRIOZOLA, M. \& VARGAS, F, - Calastro ecográfico, serológico y radiológico en hidatidosis humana. Acta gastroent. lat. amer., 15:199-211, 1985.
2. FRIDER, B.; LARRIEU, E.; ODRIOZOLA, M. \& VARGAS, F. - Calastro ecográfico de hidatidosis humana en un área endémica. Rev, ibér. parasit.. 46:257$266,1986$.

3. FRIDER, B.; LOSADA, C.; LARRIEU, E. \& ZAVALETA, O. - Hidatidosis humana portadores asintomáticos en áreas endémicas. Med. Rural. Neuq., 15:3$9,1986$.

4. LARRIEU, E.; LESTER, R.; JAUREGUI, R. \& ODRIOZOLA, M. - Epidemiología de la hidatidosis humana en la Provincia de Rio Negro. Acta gastroent. lat. amer., 16:90-108, 1986.

5. LARRIEU, E.: ZAVALETA, O.; IRIARTE, J. \& BITSCH, A. - Sistema de vigilancia epidemiológica de la hidatidosis en la Región Patagónica Argentina. Vet. Argent., 19:843-853, 1985

6. LARRIEU, E.; DE LA FUENTE, R.; AQUINO, A.; VARGAS, F. \& GUARNERA, E. - Control de la hidatidosis mediante estrategias de atencion primaria en la Provincia de Río Negro, Argentina. In: Seminario Patagónico Control Hidatidosis, 3., Usuahia, 1988. p.8.

7. MEIKE, M.; LARAUSE, B. \& GAUDEBOUT, C. Despistage echotomograhique et serologique de l' hidatidose dans un village Tunisien. In: Congreso Internacional Hidatidosis, 13, Resúmenes. España, 1985. p.39.

8. MINISTERIO DE SALUD PUBLICA Y ACCION SOCIAL. Norma Técnica y Manual de procedimientos para el Control de la Hidatidosis en la República Argentina. Buenos Aires, 1986.

9. SAINT MARTIN, G.; LARRIEU, E. \& CHIESA, J. - Ecografía de campo como método catastral en hidatidosis. Rev. argent. Radiol., 2:19-25, 1986.

10. SCHANTZ, P. - La vigilancia epidemiológica de la hidatidosis. Tórax (Montevideo), 22:203-208, 1973.

11. VARELA DIAZ, V.; GUARNERA, E. \& COLTORTI, E. - Ventajas y limitaciones de los métodos inmunológicos y de detección por imágenes para el diagnóstico de la hidatidosis. Bol. Ofic. sanit. panamer., 100:369-383, 1986.

Recebido para publicação em 08/12/1988. 